\title{
Ventilation Parameters and Thermal Comfort of Naturally and Mechanically Ventilated Offices
}

\begin{abstract}
This paper discusses thermal comfort for a postgraduate study office room in the Mechanical Engineering Department of University Putra Malaysia (UPM), which maybe either naturally ventilated or air-conditioned. Thermal comfort variables were assessed by survey of sensation of the indoor climate. Tracer gas analysis, based on the concentration decay method, was employed to determine air exchange rate, age of air, and air exchange effectiveness (AEE). When the air conditioner was working the study office had conditions within the comfort zone of the American Society of Heating, Refrigerating and Air-Conditioning Engineers (ASHRAE) Standard 55; and the occupants reported they were "slightly cool." Objective data analysis showed that the office was thermally comfortable. Under naturally ventilated conditions objective results showed that the office was uncomfortable but a subjective study revealed that students found the conditions to be "slightly warm." The neutral temperature showed a wider thermal comfort range for Malaysian students than that suggested by ASHRAE Standard 55-1992, which indicates that Malaysians are acclimatized to higher environmental temperatures. However, the result is in line with the current version of ASHRAE Standard 55-2004 that includes an adaptive comfort standard that allows warmer indoor temperatures for warmer climate zones. The results of a ventilation study indicated air flow patterns in the occupied zones, which approximated to "perfect mixing" under both ventilation conditions. The measured air exchange rate also indicated that the provision of outside air for ventilation was adequate when the room was mechanically ventilated (airconditioned). Results of over 50 survey responses to thermal comfort questions in the study room at UPM are given.
\end{abstract}

